\title{
La melodía de los cantos creoles del Set-Up en la ciudad de Bluefields
}

\author{
Nydia Taylor \\ Wellene Campbell
}

Beholden, Cotton Tree y Old Bank son los barrios tradicionales creoles de Bluefields. En ellos es donde se realizan los rituales del Set Up. Estos barrios son también, según el historiador Hugo Sujo, los más poblados por esta etnia. Fue aqui en donde se recopiló la tradición oral que ahora presentamos sobre el Set Up. Esto se hizo con el objetivo de documentar la manera autóctona con que los creoles velaban y enterraban a sus muertos y para comprobar también si esta costumbre ancestral se mantiene.

\section{¿Qué es el Set Up?}

El Set $U p$ es una serie de ritos que un grupo realiza coordinadamente al morir una persona: la vela, el entierro y el más allá son partes de un proceso donde cada una de ellas va acompañada de un conjunto de ritos los cuales están en riesgo de perderse actualmente. No toda la población conoce los rituales que se dan en estos funerales,

\section{EI Set $U p$ expresión de la solidaridad tradicional creole}

Muchos de quienes llegan a los velorios a cantar no tienen conocimiento ni idea de los procesos previos que se necesitan realizar para el funeral. Por ejemplo ignoran que se forman diferentes grupos para hacer diversos trabajos durante el Set Up. Hay quienes se dedican a la cocina y preparan la comida para los que asisten, mientras otros cuidan a los niños y limpian la casa. Están los encargados de bañar y preparar el cuerpo del occiso. También llegan carpinteros que inspeccionan el corredor de la casa y comprueban si presta las condiciones necesarias. Si no, lo arreglan antes de empezar la construcción del ataúd. Los albañiles por su parte construyen la bóveda en el cementerio, mientras quienes lideran los cantos se preparan.

El Set Up es la manifestación de la solidaridad ancestral que se fortaleció en el curso de la historia de los primeros grupos afrodescendientes explotados en América, una solidaridad de grupo que se manifiesta en las actividades productivas y, en este caso, en situaciones espirituales.

En el Set Up, cada quien coopera en la medida de sus posibilidades y en el ramo de su especialidad. Muchas de las personas acuden voluntariamente y se ofrecen para hacerse cargo de todo lo necesario, y así pueda la familia del fallecido relajarse y profundizar sobre su pérdida, la transición hacia la muerte y la aceptación del duelo.

El comportamiento de la señora Julia Benard, tal vez ilustre el grado de compromiso y el papel que asumen estos comunitarios en el Set Up, Ella comentó que cuando acudía a un Set Up preparaba su bolsa con todo lo que tenía que llevar, porque pasaba varios días fuera de su casa solidarizándose con la familia del muerto y ayudando con los trabajos. Las personas que llegaban a ayudar llevaban comida para contribuir con los gastos y para que su estadía no implicara un peso más para los dolientes.

En las ceremonias del velorio y el entierro "uno conoce quiénes son sus amigos", dijo Miss Seferina Berger (q.e.p.d.) en su lecho de enferma durante la entrevista que se le hizo en abril del 2011. Esta portadora cultural, además de ser experta en la preparación de cadáveres, tenía muchos conocimientos de medicina tradicional, fue bailarina del May Pole y amante del deporte.

El Prof. William Solomon considera que el Set Up es una tradición negra y señala que no se puede decir que es de la Costa. "Es de los negros y, por eso es parte de nuestra cultura afrodescendiente. La forma en que atendemos a nuestros muertos es diferente de como lo hacen los demás“.

La expresión de Miss Brenda Murray: ilustra ejemplarmente el extremo contrario al que se puede llegar si en el funeral no se cuenta con un Set Up: "Hemos visto personas que se quedan solos con sus difuntos". 


\section{Instrumentos del Set $U$ p}

\section{Sankey}

Es el nombre del himnario de canciones religiosas que los creoles cantan en las iglesias durante los funerales. Hay un lector que dirige los cantos, leyendo los versos de la canción para que los asistentes puedan cantarlo. Se hacía de esta manera, porque algunos ellos no podían leer y también porque muchos no tenían su propio himnario. A la persona que lee las letras de las canciones se le llama "el lector."

\section{Cánticos típicos}

Siempre hay una persona que lidera los cantos en el Set Up. Esta persona lee los versos de las canciones y luego los asistentes al velorio los repiten cantando.

Al retornar del cementerio es cuando empiezan los cantos del Set Up, aunque los portadores culturales de mayor edad expresaron que antes se cantaba desde el día del deceso. En la ciudad de Bluefields no acostumbran cantar mientras está presente el cadáver, generalmente se canta desde la media noche del Set Up hasta la madrugada, mientras que en Corn Island se canta desde el primer día.

Sweet and beloved sleep and take thy rest... cantó durante la entrevista Mr. Waldrow Joseph. Y al respecto expresó:, I love the singing, I enjoy it very much.

Yo disfrutaba oír los cantos desde el lecho de mi cama en altas horas de la noche cuando el bullicio de la gente se ha calmado y la luna brillaba como si fuera de día... Me encantaba disfrutar de esas melodias.

Mrs. Hazel Wilson expresó en la entrevista que muchas veces las personas aún en vida solicitaban las canciones que querían que les cantaran en el Set Up.

\section{Luto}

Se demuestra llevando ropa negra por un año o seis meses, dependiendo de cuál miembro de la familia ha muerto. Después del periodo inicial se usa un medio luto con ropa negra y blanca o un color bajo, como crema, violeta, $\mathrm{u}$ otros colores claros. El luto es también una manera de demostrar respeto y cariño para el difunto.

\section{Preparación del cadáver}

Los expertos utilizaban métodos naturales para preservar el cadáver y retardar su descomposición antes de enterrarlo. Los baños y ungüentos preparados a base de cal, limones agrios y especies como la nuez moscada y clavo de olor eran unos de sus métodos de preservación:

Después que moría la persona, había la creencia de que tenía que enfriarse en su propia cama, y el tiempo que toma un cuerpo en perder su temperatura son 24 horas. Anteriormente utilizaban una tabla donde acostaban al muerto, cortaban naranja agria en rodajas, colocaban el cadáver boca abajo y lo cubrían con las rodajas de naranja. Luego lo cubrían con una tela de mosquitero y así permanecía hasta el día del entierro que es cuando preparaban el cadáver para el funeral. Antes del funeral, lo bañaban y vestían. No todos bañan a sus muertos, pero nosotros los creoles sí. Cuando el difunto está completamente vestido se arregla la cama con sábana y funda blanca, se coloca al difunto encima de una almohada en medio de la cama y la otra almohada se pone debajo de su cabeza. Antes de poner al muerto en el ataúd, la gente que lo baña y cambia canta tres canciones del himnario cristiano llamado "Sankey”. (Prof. William Solomon).

\section{Tradiciones durante el velorio}

Se escogía un lugar en un patio de la vecindad, para construir el ataúd. Se usaba madera fina como caoba, cedro real o laurel. Las personas encargadas de esta tarea solicitaban la cantidad de madera que necesitaban en el aserradero y les era entregada sin costo alguno. Asimismo se conseguía la madera para reparar la baranda de la casa del muerto si estaba en mal estado, considerando que tendrían la visita de muchas personas y que debía de estar en buenas condiciones para resistir el peso de la gente.

Se suele cocinar en la casa de algún vecino y no en la casa donde está el cadáver, porque se considera que no es higiénico. Se sirve café, té o cocoa y Journey Cakes para mantenerse despiertos y poder cantar durante toda la noche.

La casa se decora con cortinas y sábanas blancas. El espejo se tapa con una cortina, sábana o tela blanca. 
Los portadores culturales de mayor edad cuentan que siempre se ha tomado licor en los velorios, pero con más cautela. La generación más joven manifiesta que es una necesidad para mantenerse despiertos toda la noche. Por su parte, la Iglesia alega que no se puede servir a dos dioses al mismo tiempo: "No es posible que las personas estén cantando los himnos religiosos y estén tomando tragos, eso no es de Dios," comentó el reverendo Palmerston Budier en la entrevista.

\section{La procesión fúnebre}

A la iglesia y al cementerio se va caminando y cargando el ataúd en hombros o bien en un vehículo. Los acompañantes visten sus mejores vestidos negros y/o blancos con negro. Una escena que se destaca son las sombrillas o paraguas que parecen ser parte de los accesorios que siempre se llevan para protegerse del sol o de la lluvia. Cuando el féretro va pasando rumbo al cementerio las casas suelen cerrar las puertas en un acto de respeto al difunto.

\section{Nine Night}

A los nueve días se celebra el "Set Up" tradicional, se le llama también "Nine Night" que da por terminados los ritos funerarios. A las doce de la noche hay una celebración en la habitación donde estuvo el difunto llamada turn up the matres, que consiste en levantar el colchón; y mientras cantan los asistentes, dos mujeres toman las sábanas blancas y las doblan, quitan las fundas y las doblan, quitan las cortinas y las doblan. Todo es colocado en el centro de la cama.

Se abren las ventanas y las puertas y nadie debe de interponerse para dejar libre el espacio para que el espíritu pueda salir de allí. El agua que estuvo en un vaso en la habitación para calmar la sed del espíritu es regada en las cuatro esquinas del cuarto y sobre la ropa en el centro de la cama, mientras se entona el himno Goodby, goodby, goodby, Adios, adiós, adiós.

"Las velas eran una belleza para la ciudad y un placer para las personas... Después de ir al cementerio, algunos se sienten tristes, pero luego se animan al oír los cantos", expresó Mr. Waldrow Joseph.

\section{Cambios en las tradiciones}

Los portadores culturales expresan que algunas manifestaciones del Set $U p$ han cambiado debido a diferentes razones, por ejemplo:
- Gracias al hielo ha variado la manera de preservar el cadáver.

- Muchas familias no quieren realizar los ritos, porque no pueden asumir los gastos.

- Ya no se hacen los ataúdes en los patios, hay lugares que ya tienen cajas construidas que no son de madera y tienen costos muy elevados. La madera es difícil de conseguir y no se consigue de buena calidad.

- Antes no se ponía música, no se iba a fiestas ni se encendía el televisor, ahora algunos se van a restaurantes después del entierro.

- Se sabe que en algunos velorios se han perdido cosas de valor, llegan muchos en busca de comida y los que ofrecen trabajar esperan una recompensa monetaria.

- Cada una de las personas entrevistadas (varones y mujeres) expresaron que la tradición del Set Up está totalmente pérdida. No se explican por qué las personas no quieren hacer el ritual de los velorios como se hacía en el pasado.

- Otro elemento que ha obligado al cambio en la celebración del Set Up es la inseguridad ciudadana.

- La inmigración de personas de otras partes del país también nos ha influenciado con sus culturas.

Hoy en día las cosas han cambiado completamente dice Ms. Julia Benard. Se ha optado por un "Memorial", se reparte un sándwich o comida y se termina la celebración en unas dos o tres horas.

Aún hay personas que se aferran a sus costumbres y desean que no muera la tradición. Con todos los datos proporcionados en esta investigación basada en fuentes orales es posible iniciar el rescate del Set Up, teniendo en cuenta que aún hay portadores demandando a sus familiares que cuando ellos mueran quieren que se practiquen estos rituales. Quieren que se cante, cocine, y que se haga el Set $U p$ de la manera tradicional.

\section{Portadores culturales del Set Up entrevistados}

Miss Elizabeth Forbes, Miss Lizzie, Sr. Waldrow Joseph, Mrs. Rose Hansack (Little Rose), Mrs. Seferina Berger, Prof. Hugo Sujo, Mrs. Lila Brown, Mrs. Brenda Murray, Dean Martin, Mrs. Julia Benard, Mrs. Erminia Nash, Mr. Arthur Nash, Mr. Marvon Woods, Rev. Palmiston Budier. 